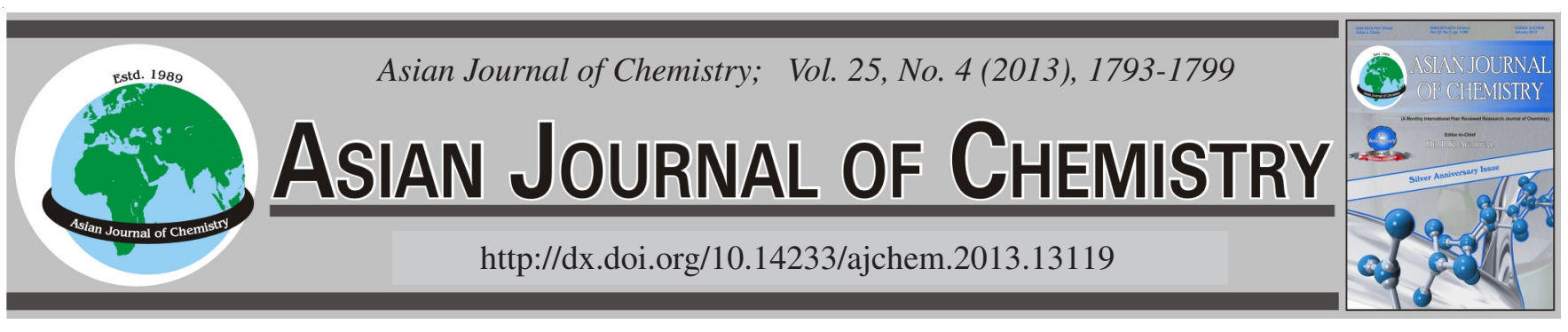

\title{
Neural Network for Modeling of Chemical Reaction Systems: Kinetics of Concentrated Acid Hydrolysis of Walnut Green Skin
}

\author{
A. Arasteh Nodeh $^{1, *}$, M. Ardjmand ${ }^{1}$, M.A. Fanaei ${ }^{2}$ and A.A. Safekordi ${ }^{1}$
}

${ }^{1}$ Department of Engineering, Science and Research Branch, Islamic Azad University, Tehran, Iran

${ }^{2}$ Department of Chemical Engineering, Faculty of Engineering, Ferdowsi University of Mashhad, Mashhad, Iran

*Corresponding author: Tel: +98 91 53164051; E-mail: aliarastehnodeh@yahoo.com

(Received: 26 November 2011;

Accepted: 3 October 2012)

AJC-12221

\begin{abstract}
Besides usage of walnut green skin as an available biomass for bioethanol production, application of neural network for modeling the conversion rates of glucose from walnut green skin by concentrated acid hydrolysis has been investigated. Due to a more complex and unknown kinetics of the investigated reaction, the proposed approach based on application of neural networks is an efficient and accurate tool to solve modeling problem. The influence of the main pretreatment variables including temperature, processing time, solid contents and acid concentration on fermentable sugar generation from walnut green skin is studied by using factorial design of experiment. Levels for pretreatment temperature $\left(65,80,90^{\circ} \mathrm{C}\right)$, process time $(120,180,240 \mathrm{~min})$, solid content $(5,10,15 \%)$ and concentration of sulfuric acid $(20,40,60 \%)$ were selected. Glucose were analyzed by HPLC and modeled by two layers neural network with different topology. Despite using simple data and a simple neural network, high accuracy was achieved. Results was compared with a quadratic equation model.
\end{abstract}

Key Words: Walnut green skin, Glucose, Acid sulfuric, Concentrated acid hydrolysis, Neural network.

\section{INTRODUCTION}

Bioethanol is a liquid biofuel which can be produced from several different biomass feedstocks. This fuel has a higher octane number, broader flammability limits, higher flame speeds and higher heat of vapourization than gasoline. Fuel ethanol production from lignocellulosic biomass is emerging as one of the most important technologies for sustainable production of renewable transportation fuels. Ethanol production process only uses energy from renewable energy sources ${ }^{1}$ and has deserved a great deal of interest in the last two decades ${ }^{2}$. But conversion technologies for producing ethanol from cellulosic biomass recourse are under development and have not been demonstrated commercially, yet ${ }^{3}$. The use of lignocelluloses materials like agricultural residue may contribute to the economy of the global conversion process. These biomass is the most abundant and attractive renewable resource in many countries for the production of ethanol ${ }^{4}$ because it does not compete with animal feed and food industry.

In 2007 , total production of walnut was $17 \times 10^{5}$ metric tons. China (503000 tons), USA (209000 tons), Turkey (184000 tons) and Iran (170000 tons) are the main producers. Walnut fruit consists of 3 main parts, meat, woody skin and green skin. Green skin consists of cellulose, hemicelluloses and lignin. Cellulose is a linear, crystalline homo polymer with a repeating unit of glucose strung together $\beta$-glucosidic linkages. The structure is rigid and harsh treatment is required to break it down ${ }^{5}$. In contrast to cellulose, which is a polymer of only glucose, hemicellulose is a hetero-polymer of Dxylose, D-glucose, D-galactose, D-mannose and L-arabinose ${ }^{6}$. The carbohydrate polymers in the green skin need to be converted to simple sugars before fermentation through a process called hydrolysis.

The production of ethanol from this lignocellulosic biomass involves the different steps of pretreatment, hydrolysis (saccharification), fermentation and ethanol recovery ${ }^{1}$. Pretreatment affects the structure of biomass by solubilizing cellulose, reducing crystallinity and increase the available surface area and pore volume of the substrate. Hydrolysis of biomass is essential for generation of fermentable sugars which are then converted to ethanol by microbal action ${ }^{1}$. Hydrolysis (saccharification) breaks down the hydrogen bonds in the hemicelluloses and cellulose fraction into their sugar components, pentose and hexose ${ }^{3}$. The reaction is catalyzed by dilute acid, concentration acid or enzymes.

Hydrolysis of lignocelluloses by concentrated sulfuric acid or hydrochloric acid is an old process. Braconnot in 1819 first discovered that cellulose can be converted to fermentable sugar 
by concentrated acids ${ }^{7}$. Concentrated acid processes are generally reported to give higher sugar yield (e.g. $90 \%$ of theoretical glucose yield) and consequently higher ethanol yield, compared to dilute-acid processes. Furthermore, the concentrated acid processes can operate at low temperature, which is a clear advantage compared to dilute acid processes. Reaction times are typically much longer than for dilute acid process $^{8}$. Sulfuric acid is the most investigated acid, although other acids such as $\mathrm{HCl}^{9}$ have also been used. However, the concentration of acid is very high in this method (e.g. 30-70 $\%$ ) and dilution and heating of the concentrated acid during the hydrolysis process make it extremely corrosive. Therefore, the process requires either expensive alloys or specialized nonmetallic constructions, such as ceramic or carbon-brick lining. The acid recovery is an energy-demanding process. In addition, when sulfuric acid is used, the neutralization process produces large amounts of gypsum ${ }^{10}$. Concentrated acid process provides a complete and rapid conversion of cellulose to glucose and hemicelluloses to 5-carbon sugars with little degradation ${ }^{11}$. Balat et al. ${ }^{11}$ performed the concentrated acid hydrolysis of mixed wood chips and found that maximum sugar recovery (78-82\%) of theoretical yield was achieved at sulfuric acid concentration $(26 \%)$ for $2 \mathrm{~h}$ of residence time. The critical factors needed to make this process economically viable are to optimize sugar recovery and cost effectively recovers the acid for recycling ${ }^{11}$. This process requires a neutralization step costly equipment and high temperature applied in the acidpretreatment which causes the production of toxic byproducts such as furfural and hydroxyl methyl furfural (HMF) ${ }^{4}$. The low temperature and pressure also minimize the degradation of sugars. It is a relatively slow process and need acid recovery, without acid recovery large lime must be use and large amounts of calcium salt is formed ${ }^{3}$. These salts have low solubility and normally removed by filtration ${ }^{12}$.

Cellulose, hemicellulose and lignin are broken down to mainly glucose, mannose or xylose and phenolic compounds during acid hydrolysis. Further decompositions occur during these process conditions yielding other unexpected compounds such as furfural from pentose and acetic acid from acetyl groups in hemicellulose. For the fermentation process, the presence of these materials in hydrolysates can hinder or prevent a subsequent fermentation step. Furfural has been reported to be a strong inhibitor for $S$. cerevisiae. It decreases significantly the $\mathrm{CO}_{2}$ evaluation rate, the cell multiplication and the total viable cell number in the early phase of fermentation $^{13}$. The inhibitory effect of acetic acid is $\mathrm{pH}$-dependent. Very high concentration of acetic acid increase acidification of cytoplasm and cell death. Two mechanisms have been proposed to explain the inhibitory effect of acetic acid, uncoupling and intracellular anion accumulation ${ }^{14}$. Therefore, hydrolysis with low concentrations of inhibitors is required.

It is important to determine the glucose concentration because this sugar is the main carbon source for most microorganisms ${ }^{15}$. Due to the difficulty in finding a strict mechanism for hydrolysis reactions, it is usual to use simplified models to determine the kinetics of the hydrolysis of lignocellulosic material to obtain sugar solutions (xylose and glucose) with low concentrations of inhibitor (furfural and acetic acid) $)^{15,16}$. In the first model (QE model), the response of variable can be predicted by following a second-order model (eqn. 1) which allows the influence of each factor on the response as well as interactions among factors to be determined ${ }^{17-21}$.

$$
\begin{gathered}
\mathrm{Y}=\mathrm{A}_{0}+\mathrm{A}_{1} \cdot \mathrm{C}+\mathrm{A}_{2} \cdot \mathrm{T}+\mathrm{A}_{3} \cdot \mathrm{S}+\mathrm{A}_{4} \cdot \mathrm{t}+\mathrm{A}_{5} \cdot \mathrm{C}^{2}+\mathrm{A}_{6} \cdot \mathrm{T}^{2} \\
+\mathrm{A}_{7} \cdot \mathrm{S}^{2}+\mathrm{A}_{8} \cdot \mathrm{t}^{2}+\mathrm{A}_{9} \cdot \mathrm{C} \cdot \mathrm{T}+\mathrm{A}_{10} \cdot \mathrm{C} \cdot \mathrm{S}+\mathrm{A}_{11} \cdot \mathrm{C} \cdot \mathrm{t}+\mathrm{A}_{12} \cdot \mathrm{T} \cdot \mathrm{S} \\
+\mathrm{A}_{13} \cdot \mathrm{T} \cdot \mathrm{t}+\mathrm{A}_{14} \cdot \mathrm{S} \cdot \mathrm{t}
\end{gathered}
$$

The study of pretreatment performance of walnut green skin by concentrated sulfuric acid was addressed by performing the experimental design in which process temperature $\left(\mathrm{T},{ }^{\circ} \mathrm{C}\right)$, process time $(\mathrm{t}, \mathrm{min})$, solid content $(\mathrm{S}, \%)$ and acid concentration $(\mathrm{C}, \%)$, were selected as factors and glucose concentration $(\mathrm{Gl}, \%)$ was considered as response $(\mathrm{Y})$. In second model, the models usually associated with dilute acid hydrolysis were first proposed by Saeman ${ }^{22}$, for the hydrolysis of cellulose from Douglas fir wood using sulfuric acid. The models proposed in the literature use irreversible pseudohomogeneous first-order reactions ${ }^{23-26}$.

Polymer $\stackrel{\mathbf{k}_{\mathbf{1}}}{\longrightarrow}$ monomer $\stackrel{\mathbf{k}_{\mathbf{2}}}{\longrightarrow}$ decomposition products where $\mathrm{k}_{1}$ is the rate of conversion of polymer (glucan, xylan) to monomer (glucose, xylems) and $\mathrm{k}_{2}$ is the rate of decomposition of monomers.

Despite all effort to find a appropriate kinetic model to describe acid hydrolysis of biomass, success in mathematical model many researcher have turned their attention to ANNs and have successfully applied them for modeling these processes ${ }^{27-30}$. Recently the application of neural network has become more popular in chemical engineering particularly chemical hydrolysis. Artificial neural networks can be considered as a simplified mathematical formulation of central neural system in human being. They are implemented through computer program or electronic hardware devices. The major advantage of this powerful tool is that, it can be synthesized without detailed knowledge of underlying process ${ }^{31}$. The application of neural networks seem to be a promising tool to solve modeling problems for the cases where as a result of insufficient knowledge the governing mechanism can not be formulated. The flexibility and accuracy of neural network depend on the net architecture and treatment of available experimental data ${ }^{32-34}$. Their applications include pattern classification, control and prediction. The aim of this work is to propose a methodology based on artificial neural network for concentrated acid hydrolysis.

\section{EXPERIMENTAL}

Raw material: Walnut green skin (WGS) was collected in September of 2009 from Spidan village (North Khorasan, Iran). It was washed by distilled water, air dried and milled using vibratory disc mill (Retsch RS 100) to particle size smaller than 50 micrometers and stored in sealed plastic bags at the room temperature. For the determination of the chemical composition of the walnut green skin, preparation of the test specimens was carried out according to TAPPI T $257 \mathrm{om}$ (1985) standard. Extracted materials, lignin and ash contents were determined according to TAPPI standards T $204 \mathrm{om}$ (1988), T 222 om (1988), T 211 om (1988) standards, respectively. The hemicellulose and cellulose contents were determined according to Wise's chlorite and K. Rschner-Hoffner nitric acid methods ${ }^{35,36}$. The resulted composition of walnut green skin is shown in Table-1. 


\begin{tabular}{lc}
\hline \multicolumn{2}{c}{ COMPOSITION OF WALNUT GREEN SKIN } \\
\hline Composition & Dry weight $(\%)$ \\
\hline Cellulose & 21.5 \\
Hemicellulose & 13.25 \\
Extractive M & 18.25 \\
Lignin & 26.07 \\
Ash & 20.93 \\
\hline
\end{tabular}

Experimental condition: Based on previous experience with concentrated acid hydrolysis to ensure a broad range of response, three levels for each factor including temperature, acid concentration, solid content and time were considered and walnut green skin was pretreated at 84 different operational conditions. Selected conditions were shown in Table-2a-c. Every experiment was repeated for three times and the average value was reported.

Pilot plant: Dried walnut green skin was treated with 20, 40, 60 wt \% sulfuric acid in screw-capped laboratory bottles (Pyrex bottles) in a hot water jacket with an electric heater and a temperature controller ( Fig. 1) at $65,80,90{ }^{\circ} \mathrm{C}$ for 2,3 , $4 \mathrm{~h}$ with agitation by a laboratory mixer, respectively. A distiller was used to prevent water evaporation. Solid to liquid ratio of 5,10 and $15 \%$ was applied, respectively. Once the temperature of reaction mixture reached to the designed point, pretreatment time was started. At the end of each run the bottle was removed from the heating jacket and put in a cool water bath, sodium hydroxide was added to adjust until its $\mathrm{pH}$ value around 7 and then solids were separated by filtering, washed with distilled water and final solution reached to $1000 \mathrm{~mL}$. A $200 \mathrm{~mL}$ sample of the solution was analyzed by HPLC.

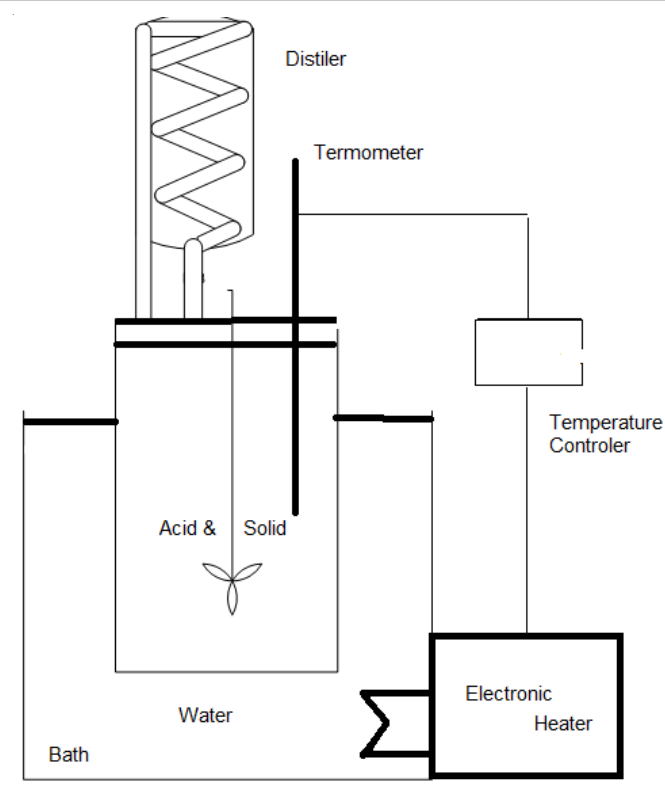

Fig. 1. Experimental setup of hydrolysis reactor

Analytical methods: The composition of the hydrolyzate from acid hydrolysis (glucose, xylose, mannose, arabinose, galactose, furfural and acetic acid) was determined by HPLC (JASCO model). Glucose, xylose, galactose, mannose and arabinose were analyzed by bio-rad column Aminex HPX$87 \mathrm{P}$ and detected by RI detector at $40{ }^{\circ} \mathrm{C}$ and acetic acid and furfural were analyzed by bio-rad column Aminex HPX-87H and detected by UV detector at $210 \mathrm{~nm}$. The results were shown as the percentage of $\mathrm{g}$ product/g raw material (e.g. $2 \% \mathrm{~g}$ glucose/ $\mathrm{g}$ raw material) in Table- 2 and Figs. 2 and 3.

\begin{tabular}{|c|c|c|c|c|c|c|c|c|c|}
\hline \multicolumn{10}{|c|}{$\begin{array}{c}\text { TABLE-2a } \\
\text { OPERATION CONDITIONS AND RESULTS OF ACID HYDROLYSI }\end{array}$} \\
\hline Run & Temp $\left({ }^{\circ} \mathrm{C}\right)$ & $\mathrm{t}(\mathrm{min})$ & $\mathrm{H}_{2} \mathrm{SO}_{4}(\%)$ & WGS [\%] & Glucose (\%) & C5 $(\%)$ & C6 $(\%)$ & Furfural (\%) & Acetic acid (\%) \\
\hline 1 & 65 & 120 & 20 & 5 & 2.5 & 0.288 & 2.93 & 0.355 & 2.3 \\
\hline 2 & 65 & 180 & 20 & 5 & 3.7 & 0.144 & 4.06 & 0.991 & 2.61 \\
\hline 3 & 65 & 240 & 20 & 5 & 4.8 & 1.178 & 5.96 & 1.694 & 4.08 \\
\hline 4 & 65 & 120 & 20 & 10 & 2.95 & 1.042 & 3.11 & 0.606 & 2.57 \\
\hline 5 & 65 & 180 & 20 & 10 & 4.3 & 0.96 & 4.15 & 1.242 & 2.89 \\
\hline 6 & 65 & 240 & 20 & 10 & 5.6 & 1.99 & 6.07 & 1.9 & 4.36 \\
\hline 7 & 65 & 120 & 20 & 15 & 3.8 & 1.44 & 4.64 & 1.086 & 3.21 \\
\hline 8 & 65 & 180 & 20 & 15 & 5.1 & 1.354 & 5.69 & 1.722 & 3.53 \\
\hline 9 & 65 & 240 & 20 & 15 & 6.1 & 2.39 & 7.6 & 2.38 & 5 \\
\hline 10 & 80 & 120 & 20 & 5 & 3.3 & 0.513 & 3.94 & 0.76 & 2.8 \\
\hline 11 & 80 & 180 & 20 & 5 & 4.4 & 0.43 & 4.99 & 1.396 & 3.12 \\
\hline 12 & 80 & 240 & 20 & 5 & 5.3 & 1.46 & 6.91 & 2.056 & 4.59 \\
\hline 13 & 80 & 120 & 20 & 10 & 3.7 & 1.327 & 4.05 & 1.011 & 3.08 \\
\hline 14 & 80 & 180 & 20 & 10 & 4.7 & 1.243 & 5.10 & 1.647 & 3.4 \\
\hline 15 & 80 & 240 & 20 & 10 & 6 & 2.277 & 7.01 & 2.305 & 4.87 \\
\hline 16 & 80 & 120 & 20 & 15 & 4.9 & 1.723 & 5.59 & 1.491 & 3.72 \\
\hline 17 & 80 & 180 & 20 & 15 & 6.2 & 1.64 & 6.64 & 2.127 & 4.04 \\
\hline 18 & 80 & 240 & 20 & 15 & 7 & 2.67 & 8.55 & 2.785 & 5.51 \\
\hline 19 & 90 & 120 & 20 & 5 & 4 & 0.776 & 4.09 & 1.445 & 3.9 \\
\hline 20 & 90 & 180 & 20 & 5 & 5.7 & 0.692 & 5.95 & 2.081 & 4.21 \\
\hline 21 & 90 & 240 & 20 & 5 & 6.5 & 1.728 & 7.86 & 2.739 & 5.68 \\
\hline 22 & 90 & 120 & 20 & 10 & 4.5 & 1.59 & 5.01 & 1.696 & 4.17 \\
\hline 23 & 90 & 180 & 20 & 10 & 5.9 & 1.566 & 6.00 & 2.332 & 4.49 \\
\hline 24 & 90 & 240 & 20 & 10 & 7.0 & 2.54 & 7.97 & 2.99 & 5.96 \\
\hline 25 & 90 & 120 & 20 & 15 & 6 & 1.986 & 6.54 & 2.176 & 4.81 \\
\hline 26 & 90 & 180 & 20 & 15 & 7.6 & 1.902 & 7.6 & 2.812 & 5.13 \\
\hline 27 & 90 & 240 & 20 & 15 & 8.5 & 2.936 & 9.5 & 3.47 & 6.6 \\
\hline
\end{tabular}


TABLE-2b

OPERATION CONDITIONS AND RESULTS OF ACID HYDROLYSIS USING WALNUT GREEN SKIN (WGS) (40\% ACID)

\begin{tabular}{|c|c|c|c|c|c|c|c|c|c|}
\hline Run & Temp $\left({ }^{\circ} \mathrm{C}\right)$ & $\mathrm{t}(\mathrm{min})$ & $\mathrm{H}_{2} \mathrm{SO}_{4}(\%)$ & WGS (\%) & Glucose (\%) & C5 (\%) & C6 (\%) & Furfural (\%) & Acetic acid (\%) \\
\hline 1 & 65 & 120 & 40 & 5 & 4.04 & 0.33 & 5.23 & 0.005 & 3.71 \\
\hline 2 & 65 & 180 & 40 & 5 & 5.47 & 0.25 & 6.27 & 0.03 & 4.03 \\
\hline 3 & 65 & 240 & 40 & 5 & 6.6 & 1.283 & 8.19 & 0.439 & 5.5 \\
\hline 4 & 65 & 120 & 40 & 10 & 4.25 & 1.147 & 5.33 & 0.01 & 4 \\
\hline 5 & 65 & 180 & 40 & 10 & 5.66 & 1.063 & 6.39 & 0.032 & 4.31 \\
\hline 6 & 65 & 240 & 40 & 10 & 6.72 & 2.10 & 8.29 & 0.69 & 5.78 \\
\hline 7 & 65 & 120 & 40 & 15 & 5.03 & 1.54 & 6.87 & 0.01 & 4.63 \\
\hline 8 & 65 & 180 & 40 & 15 & 6.43 & 1.46 & 7.92 & 0.512 & 4.95 \\
\hline 9 & 65 & 240 & 40 & 15 & 7.32 & 2.50 & 9.83 & 1.17 & 6.42 \\
\hline 10 & 80 & 120 & 40 & 5 & 5.15 & 0.62 & 6.18 & 0.45 & 4.22 \\
\hline 11 & 80 & 180 & 40 & 5 & 6.54 & 0.54 & 7.21 & 0.186 & 4.54 \\
\hline 12 & 80 & 240 & 40 & 5 & 7.41 & 1.57 & 9.13 & 0.844 & 6.01 \\
\hline 13 & 80 & 120 & 40 & 10 & 5.52 & 1.43 & 6.28 & 0.01 & 4.5 \\
\hline 14 & 80 & 180 & 40 & 10 & 6.99 & 1.35 & 7.33 & 0.437 & 4.81 \\
\hline 15 & 80 & 240 & 40 & 10 & 7.89 & 2.38 & 9.25 & 1.095 & 6.28 \\
\hline 16 & 80 & 120 & 40 & 15 & 6.7 & 1.83 & 7.82 & 0.281 & 5.14 \\
\hline 17 & 80 & 180 & 40 & 15 & 8.26 & 1.74 & 8.87 & 0.917 & 5.45 \\
\hline 18 & 80 & 240 & 40 & 15 & 9.07 & 2.78 & 10.78 & 1.575 & 6.92 \\
\hline 19 & 90 & 120 & 40 & 5 & 6.32 & 0.88 & 7.13 & 0.235 & 5.31 \\
\hline 20 & 90 & 180 & 40 & 5 & 7.91 & 0.79 & 8.19 & 0.871 & 5.63 \\
\hline 21 & 90 & 240 & 40 & 5 & 8.83 & 1.83 & 10.09 & 1.53 & 7.1 \\
\hline 22 & 90 & 120 & 40 & 10 & 6.69 & 1.69 & 7.24 & 0.486 & 5.59 \\
\hline 23 & 90 & 180 & 40 & 10 & 8.30 & 1.61 & 8.29 & 1.122 & 5.9 \\
\hline 24 & 90 & 240 & 40 & 10 & 9.18 & 2.64 & 10.21 & 1.78 & 7.37 \\
\hline 25 & 90 & 120 & 40 & 15 & 8.12 & 2.09 & 8.78 & 0.966 & 6.23 \\
\hline 26 & 90 & 180 & 40 & 15 & 9.84 & 2.80 & 9.04 & 1.602 & 6.54 \\
\hline 27 & 90 & 240 & 40 & 15 & 10.62 & 3.04 & 11.74 & 2.26 & 8.01 \\
\hline
\end{tabular}

TABLE-2c

OPERATION CONDITIONS AND RESULTS OF ACID HYDROLYSIS USING WALNUT GREEN SKIN (WGS) (60\% ACID)

\begin{tabular}{|c|c|c|c|c|c|c|c|c|c|}
\hline Run & Temp $\left({ }^{0} \mathrm{C}\right)$ & $t(\min )$ & $\mathrm{H}_{2} \mathrm{SO}_{4}(\%)$ & WGS (\%) & Glucose $(\%)$ & $\mathrm{C} 5(\%)$ & $\mathrm{C6}(\%)$ & Furfural (\%) & Acetic acid $(\%)$ \\
\hline 1 & 65 & 120 & 60 & 5 & 0 & 0 & 0 & 0 & 2.55 \\
\hline 2 & 65 & 180 & 60 & 5 & 0 & 0 & 0 & 0 & 2.87 \\
\hline 3 & 65 & 240 & 60 & 5 & 0.155 & 0 & 1.33 & 0.903 & 4.34 \\
\hline 4 & 65 & 120 & 60 & 10 & 0.009 & 0 & 0 & 0 & 2.83 \\
\hline 5 & 65 & 180 & 60 & 10 & 1.21 & 0 & 0 & 0 & 3.15 \\
\hline 6 & 65 & 240 & 60 & 10 & 2.346 & 0.676 & 1.589 & 0.339 & 4.62 \\
\hline 8 & 65 & 180 & 60 & 15 & 1.41 & 0.038 & 1.209 & 0.161 & 3.79 \\
\hline 9 & 65 & 240 & 60 & 15 & 2.54 & 1.072 & 3.118 & 0.819 & 5.26 \\
\hline 10 & 80 & 120 & 60 & 5 & 0 & 0 & 0 & 0 & 3.06 \\
\hline 11 & 80 & 180 & 60 & 5 & 0 & 0 & 0 & 0 & 3.38 \\
\hline 12 & 80 & 240 & 60 & 5 & 0.54 & 0.147 & 2.109 & 0.493 & 4.85 \\
\hline 13 & 80 & 120 & 60 & 10 & 0.27 & 0 & 0 & 0.55 & 3.34 \\
\hline 14 & 80 & 180 & 60 & 10 & 1.6 & 0 & 0.546 & 0.61 & 3.65 \\
\hline 16 & 80 & 120 & 60 & 15 & 0.467 & 0.407 & 1.103 & 0 & 3.98 \\
\hline 17 & 80 & 180 & 60 & 15 & 1.8 & 0.323 & 2.147 & 0.566 & 4.29 \\
\hline 18 & 80 & 240 & 60 & 15 & 2.93 & 1.357 & 4.063 & 1.224 & 5.76 \\
\hline 19 & 90 & 120 & 60 & 5 & 0.293 & 0 & 0 & 0 & 4.15 \\
\hline 20 & 90 & 180 & 60 & 5 & 0.888 & 0 & 0.843 & 0.52 & 4.47 \\
\hline 21 & 90 & 240 & 60 & 5 & 2.02 & 0.41 & 3.37 & 1.178 & 5.94 \\
\hline 22 & 90 & 120 & 60 & 10 & 1.75 & 0.274 & 0.526 & 0.135 & 4.43 \\
\hline 23 & 90 & 180 & 60 & 10 & 3.08 & 0.19 & 1.6 & 0.771 & 4.74 \\
\hline 24 & 90 & 240 & 60 & 10 & 4.21 & 1.224 & 3.486 & 1.429 & 6.21 \\
\hline 25 & 90 & 120 & 60 & 15 & 1.94 & 0.67 & 2.06 & 0.615 & 5.07 \\
\hline 26 & 90 & 180 & 60 & 15 & 3.276 & 0.586 & 3.114 & 1.251 & 5.38 \\
\hline 27 & 90 & 240 & 60 & 15 & 4.41 & 1.62 & 5.02 & 1.91 & 6.65 \\
\hline
\end{tabular}




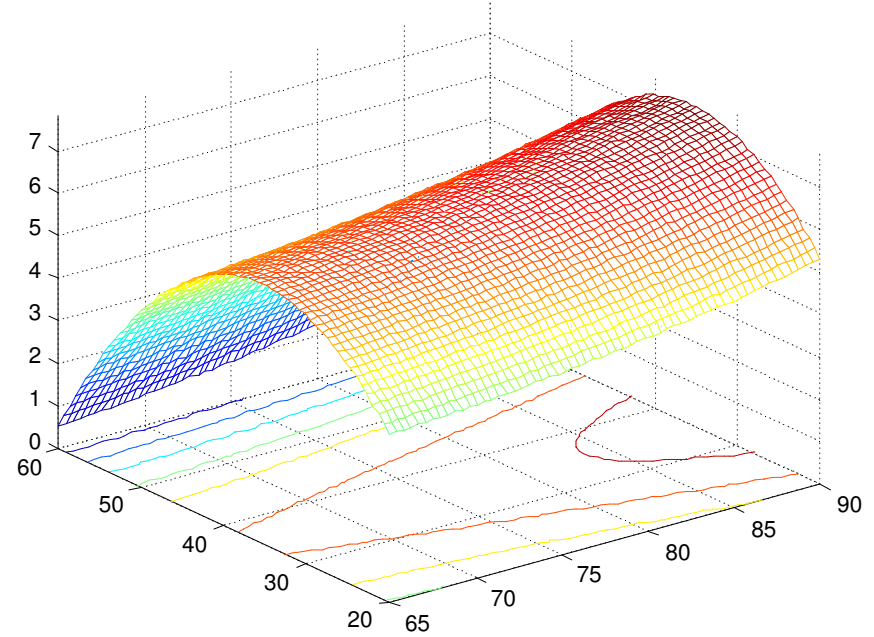

Fig. 2. Response surface for glucose recovery in liquid phase as a function of acid concentration and temperature according to the QE model

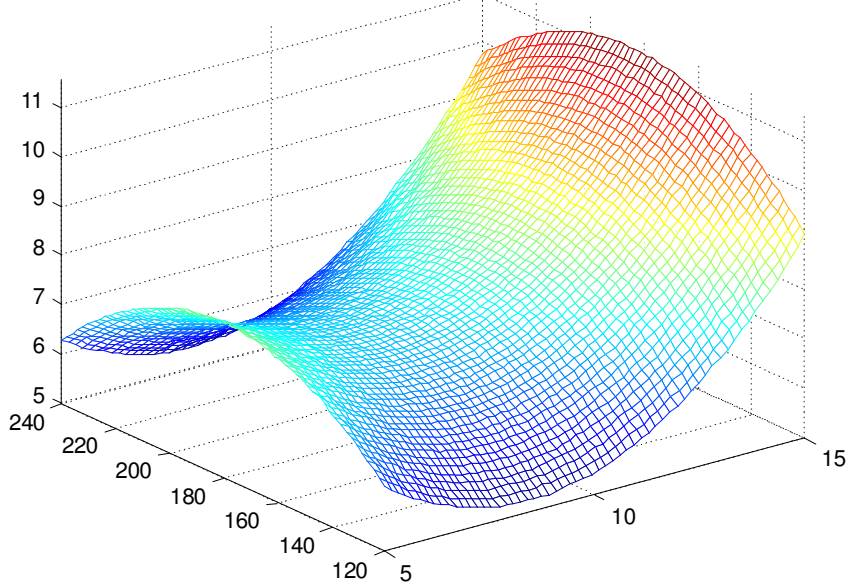

Fig. 3. Response surface for glucose recovery in liquid phase as a function of solid content and time according to the QE model

Neural network architecture: In this study, a systematic methodology has been applied to develop two multilayer feed (MLP) forward fully connected neural network which would be used for monitoring the previously described pilot plant. Multilayer feed networks are the most commonly used one for the function approximation. This multilayer feed networks consist of groups of interconnected neurons arranged in layers corresponding to input layer, hidden and output layers (Fig. 4). The inputs of the multilayer feed are temperature, acid concentration, solid content and reaction time while the output is glucose concentration. The network resembles an input/output model, whose parameters are synaptic weights and biases. This type of network has the potential of approximating most types of non-linear functions, irrespective how much they are complex. According to Vafaei et al. $^{31}$, a multilayer feed network that has only one hidden layer is able to approximate almost any type of nonlinear mapping.

The main goal when designing a neural network model is to achieve high generation ability, which means that reasonable model response is obtained for data not used during the model development. At this point, it is assumed that the training set is representative of the population and that the test data set comes from the same population ${ }^{34}$, for this reason, the data was split into 79 experiments a training set and 5 experiments as independent test set to assess the generation ability of the developed ANNs.

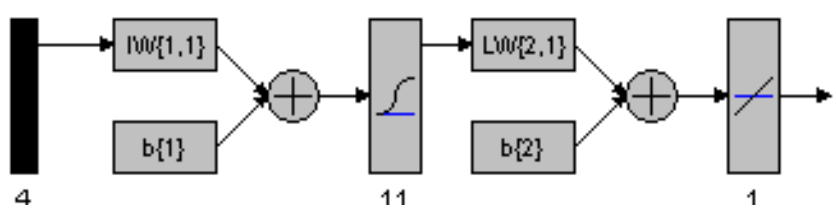

Fig. 4. Schematic of the MLP network used in this study

During the training algorithm, input data are fed to the input layer of the network and the difference between the output layer results and the desired outputs (i.e., network error) is used as a criterion for adjustment of network's synaptic weights and biases. At the beginning, all synaptic weights and biases are initialized randomly. Then, the network is trained based on an error index and an optimization algorithm, until it correctly simulates the input/output mapping. The required numbers of training data points and hidden layer neurons are the two challenges that have to be tackled appropriately. The determination of the number of nodes for the hidden layers is often done by trial and error. Too few neurons in the hidden layer prevent the network to get trained appropriately. On the other hand, too many neurons causes the network to respond very well at the training points, but when the network is exposed to new data leads to unacceptably large errors. These problems that occur during neural network training is called "overfitting". Indeed, the network has memorized the training examples, but it has not learned to set up a general correlation between input and output variables. One solution to the overfitting problem is to divide the data points into the training and validation or test data ${ }^{31}$.

Six different net topology were considered with different number of neurons (Table-3), all ANNs consisted of three layers that is only one hidden layer was used between the input and output layers (Fig. 4). Output layer of first neurons was input layer of second. Two functions were chosen for first neurons as activation function, sigmoid and tang sic. The

\begin{tabular}{|c|c|c|c|c|c|c|}
\hline \multicolumn{7}{|c|}{$\begin{array}{c}\text { TABLE-3 } \\
\text { NET TOPOLOGY AND RESULTS }\end{array}$} \\
\hline Net & Topology & First Activation function & Second activation function & MSE & Repeat & ARE \\
\hline 1 & $4-6-1$ & Tansig & Purlin & 0.01682 & 125 & 0.351 \\
\hline 2 & $4-6-1$ & Logsig & Purlin & 0.0644 & 1000 & 0.4 \\
\hline 3 & $4-8-1$ & Tansig & Purlin & 0.01695 & 180 & 0.099 \\
\hline 4 & $4-8-1$ & Logsig & Purlin & 0.01698 & 142 & 0.148 \\
\hline 5 & 4-11-1 & Tansig & Purlin & 0.001790 & 500 & 0.145 \\
\hline
\end{tabular}


neurons in the output layer has linear transfer functions. Supervized learning was used to train different ANNs created by varying the number of neurons in the hidden layer. During the training process, the mean squared error function was minimized by adjusting the network parameters.

\section{RESULTS AND DISCUSSION}

Table-3 represents the results of trial and error calculations used to determine the number of neurons in the hidden layer. According to this table, it is clear that the trained MLP that has one hidden layer with 11 logsig sigmoid neurons has a lower average relative error $(\mathrm{ARE}=0.048)$ for test data. Therefore, it is selected as the most suitable network to simulate the concentrated acid hydrolysis process. Training data were fitted with a mean square error (MSE) about 0.017. Fig. 5 show the training behaviour. After 64 repeat the result was achieved.

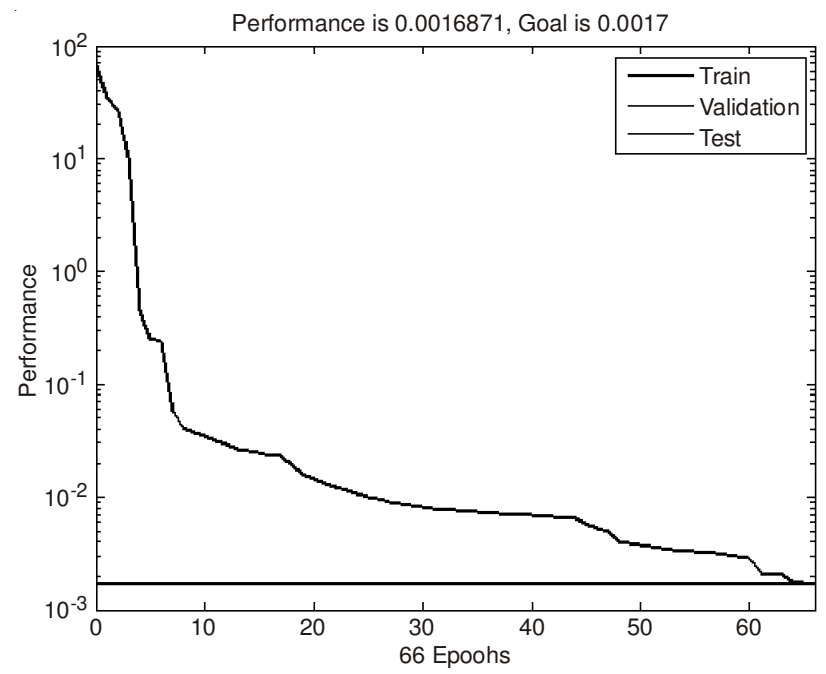

Fig. 5. Training behaviour of the MLP network used in this study

In Fig. 6, the correlation between the network estimations and experimental data is illustrated with best linear fit and the correlation coefficient. According to these results, the proposed MLP follows the experimental data with a well accuracy. The $R$ value of 0.997 indicates a good correlation among simulation results and experimental data. The network simulation results versus experimental test data are presented in Fig. 7. Although the developed MLP never has seen the test data, it can reasonably simulate the behaviour of the hydrolysis in the test region. The value of the correlation coefficient for the test data is 0.914 , which indicates sufficiently good correlation between prediction and experimental test data.

\section{Conclusion}

This work confirm that walnut green skin can be considered as a suitable feed stock for sugar production in bioethanol production process. Concentrated acid hydrolysis helps to reach the fermentable sugar in normal process conditions. This process could be model by a neural networks. According to this study, it is clear that the trained MLP that has one hidden layer with 11 tangent sigmoid neurons has a lower average relative error for test data. Therefore, it is selected as the most suitable network to simulate the concentrated acid hydrolysis process.

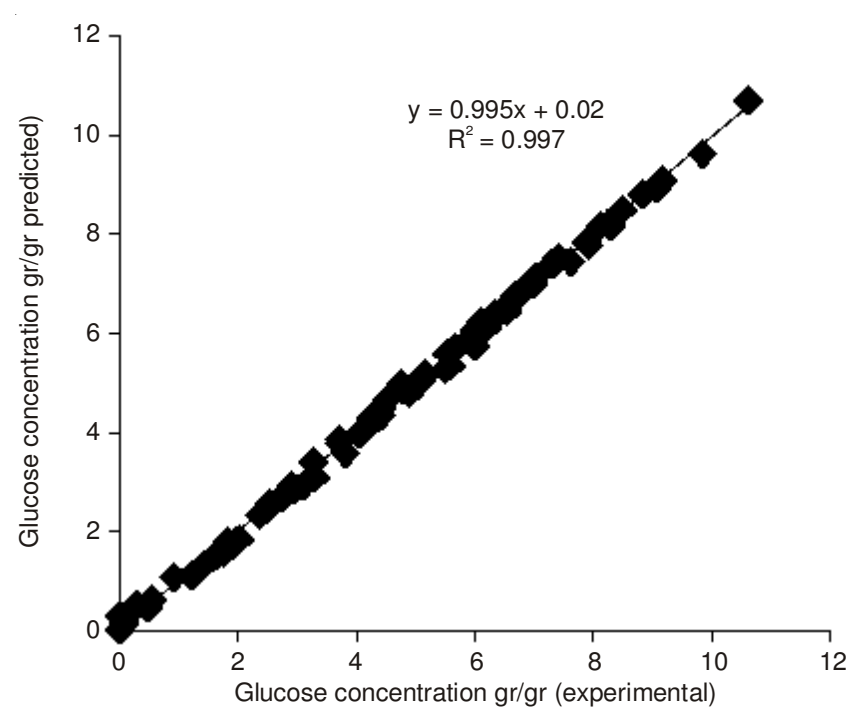

Fig. 6. Experimental versus predicted values of glucose concentration (gr/ gr walnut green skin) for training (79 runs) and validation (5 runs)

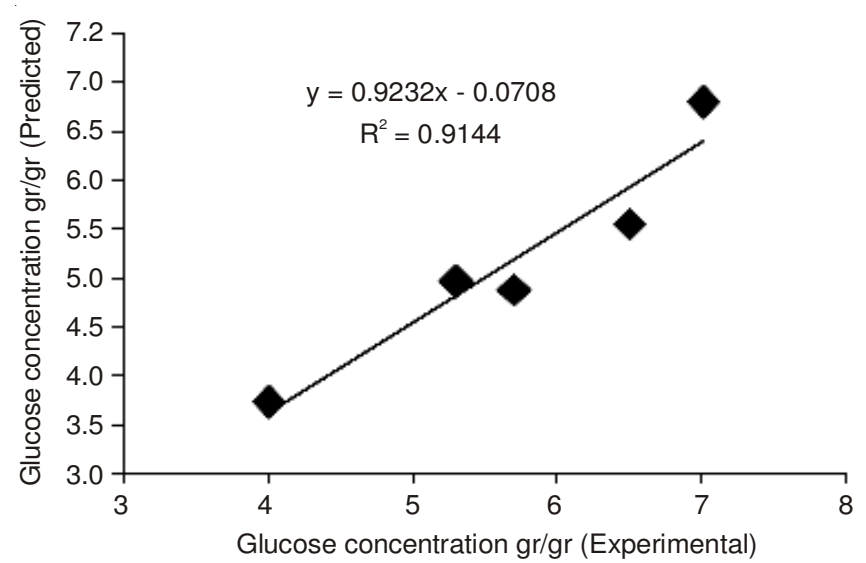

Fig. 7. Experimental versus predicted values of glucose concentration(gr/ gr walnut green skin) for validation (5 runs)

\section{REFERENCES}

1. R.K. Sukumaran, R.R. Singhania, G.M. Mathew and A. Pandey, Renewable Energy, 34, 421 (2009).

2. I. Romero, E. Ruiz, E. Castro and M. Maya, Chem. Eng. Res. Des., 88, 633 (2010).

3. A. Demirbas, Energy Sour, 27, 327 (2005).

4. J.W. Kim and G. Mazza, Ind. Crops Prod., 28, 346 (2008).

5. K.A. Gray, L. Zhao and M. Emptage, Curr. Opin. Chem. Biol., 10, 141 (2006).

6. G. Shama, Proc. Biochem., 23, 138 (1988).

7. E. Sherrard and F. Kressman, Ind. Eng. Chem., 37, 5 (1945).

8. A.K. Chandel, E.S. Chan, R. Rudravaram, M.L. Narasu, L. Venkateswar and P. Ravindra, Biotechnol. Mol. Biol. Rev., 2, 14 (2007).

9. A. Hashem and M. Rashad, Egypt J. Food Sci., 21, 171 (1993).

10. M.T. Taherzadeand and K. Karimi, Bioresources, 2, 472 (2007).

11. M. Balat, H. Balat and C. Oz, Prog. Ener. Combust. Sci., 34, 551 (2008).

12. P. Lenihan, A. Orozco, E. O'nill, M.N.M. Ahmad, D.W. Rooney and G.M. Walker, Chem. Eng. J., 156, 395 (2010).

13. E. Plamqvist, J.S. Almeida and B. Hahn, Biotechnol. Bioengg., 62, 447 (1997).

14. E. Palmqvist and B. Hahn-Hägerdal, Bioresour. Technol., 74, 25 (2000).

15. R. Aguilar, J.A. Ramirez, G. Garrote and M. Vazquez, J. Food. Eng., 55, 309 (2002).

16. T. Rogalinski, T. Ingram and G. Brunner, J. Supercrit. Fluids, 47, 54 (2008).

17. E. Castro, M. Diaz, C. Cara, E. Ruiz and M. Romero I.M. Moya, Bioresour. Technol., 102, 1270 (2011).

18. T. Jeong, B. Um, J. Kim and K. Oh, Appl. Biochem. Biotechnol., 161, 22 (2010). 
19. J. Zhou, Y.H. Wang, J. Chu, L.Z. Luo, Y.P. Zhuang and S.L. Zhang, Bioresour. Technol., 100, 819 (2009).

20. G. Luo, F. Talennia, D. Krakahev, L. Xie, Q. Zhou and I. Angelidaki, Bioresour. Technol., 102, 1433 (2011).

21. M.A. Bezerra, R.E. Santelli, E.P. Oliviera, L.S. Villar and L.A. Escaleira, Talanta, 76, 965 (2008).

22. J.F. Saeman, Ind. Eng. Chem., 37, 43 (1945).

23. T. Rogalinski, T. Ingram and G. Brunner, J. Supercrit. Fluids, 47, 54 (2008).

24. L.A. Malester, M. Green, S. Kimchie and G. Shelef, Biol. Wastes, 26, 115 (1988).

25. L.A. Malester, M. Green and G. Shelef, Ind. Eng. Chem. Res., 31, 1998 (1992).

26. A. Orozco, M. Ahmad, D. Rooney and G.M. Walker, Proc. Safety Environ. Protect. Trans. IChemE, Part B, 85, 446 (2007).

27. Y. Zhang, X. Jing-Liang and Z.H. Yuan, Modeling and Prediction in the Enzymatic Hydrolysis of Cellulose Using Artificial Neural Networks, Fifth International Conference on Natural Computation, 28 December, pp. 158-162 (2009).
28. E. Rivera, S. Rabelo, D. Garcia, R. Filho and A. Costa, J. Chem. Technol. Biotechnol., 85, 983 (2010).

29. R. Rashid, H. Jamaluddin and N. Amin, Appl. Artific. Intellig., 20, 1 (2006).

30. Y. Daizo, K. Masaaki, S. Satoshi, N. Kiyotaka and K. Hideki, J. Phys. Chem., 113, 3181 (2009).

31. M.T. Vafaei, R. Eslamloueyan and Sh. Ayatollahi, Chem. Eng. Res. Design, 87, 997 (2009).

32. E.J. Molga, B.A.A. van Woezik and K.R. Westerterp, Chem. Eng. Process., 39, 323 (2000).

33. A. Abilov and Z. Zeybek, Chem. Eng. Process., 39, 449 (2000).

34. D. Aguado, J. Ribes, T. Montoya, J. Ferrera and A. Secob, Comp. Chem. Eng., 33, 465 (2009).

35. M.R. Rowell and A. Young, Paper and Composite from Agrobased Resources, CRC Press, p. 46 (1997).

36. L.E. Wise, M. Murphy and D'Adieco, Pap. Trade J., 122, 35 (1946). 